\title{
Vitamin-mediated regulation of intestinal immunity
}

\author{
Jun Kunisawa ${ }^{1,2,3,4,5}$ * and Hiroshi Kiyono ${ }^{2,3,4,6,7}$ * \\ 1 Laboratory of Vaccine Materials, National Institute of Biomedical Innovation, Osaka, Japan \\ 2 Division of Mucosal Immunology, Department of Microbiology and Immunology, The Institute of Medical Science, The University of Tokyo, Tokyo, Japan \\ ${ }^{3}$ International Research and Development Center for Mucosal Vaccines, The Institute of Medical Science, The University of Tokyo, Tokyo, Japan \\ ${ }^{4}$ Core Research for Evolutional Science and Technology (CREST), Japan Science and Technology Agency, Tokyo, Japan \\ ${ }^{5}$ Graduate School of Pharmaceutical Sciences, Osaka University, Osaka, Japan \\ ${ }^{6}$ Department of Medical Genome Science, Graduate School of Frontier Science, The University of Tokyo, Chiba, Japan \\ ${ }^{7}$ Graduate School of Medicine, The University of Tokyo, Tokyo, Japan
}

Edited by:

Cecil Czerkinsky, Göteborg University,

Sweden

Reviewed by:

Andreas Diefenbach, University of

Freiburg, Germany

Makoto Iwata, Tokushima Bunri

University, Japan

*Correspondence:

Jun Kunisawa, Laboratory of Vaccine

Materials, National Institute of

Biomedical Innovation, 7-6-8

Saito-Asagi, Ibaraki, Osaka 567-0085,

Japan

e-mail:kunisawa@nibio.go.jp;

Hiroshi Kiyono, Division of Mucosal

Immunology, Department of

Microbiology and Immunology, The

Institute of Medical Science, The

University of Tokyo, 4-6-1

Shirokanedai, Minato-ku, Tokyo

108-8639, Japan

e-mail: kiyono@ims.u-tokyo.ac.jp
The intestine is exposed continuously to complex environments created by numerous injurious and beneficial non-self antigens. The unique mucosal immune system in the intestine maintains the immunologic homeostasis between the host and the external environment. Crosstalk between immunocompetent cells and endogenous (e.g., cytokines and chemokines) as well as exogenous factors (e.g., commensal bacteria and dietary materials) achieves the vast diversity of intestinal immune functions. In addition to their vital roles as nutrients, vitamins now also are known to have immunologically crucial functions, specifically in regulating host immune responses. In this review, we focus on the immunologic functions of vitamins in regulating intestinal immune responses and their roles in moderating the fine balance between physiologic and pathologic conditions of the intestine.

Keywords: intestinal immunity, vitamin, IgA, regulatory $\mathrm{T}$ cells, allergy, inflammation

\section{INTRODUCTION}

The primary physiologic function of intestine is to serve as the chief site of nutrient absorption into the body. However, intestinal tissues also comprise a unique immune system that can discriminate between pathogens and harmless or beneficial antigens such as commensal microorganisms and dietary constituents (1). To prevent unnecessary inflammatory responses and hypersensitivity to harmless or beneficial materials, the intestinal immune system usually becomes unresponsive to these factors through the induction of oral tolerance (2). At same time, the intestinal immune system acts as the first line of defense against pathogens. For the coordinated operation of this complex network, the intestinal immune system is customized with cooperative immunocompetent cells, including the specialized antigen-sampling $\mathrm{M}$ cells; antigen-presenting cells [e.g., dendritic cells (DCs) and macrophages]; IgA-producing plasma cells (PCs); polarized CD4 ${ }^{+}$ $\mathrm{T}$ cells such as regulatory $\mathrm{T}\left(\mathrm{T}_{\text {reg }}\right)$, Th1, Th2, and Th17 cells; mast cells; and innate lymphoid cells $(1,3,4)$. Accumulating evidence has demonstrated that the disruption of oral tolerance underlies pathogenic conditions such as intestinal inflammation and food allergy (5).

Coordination of the numerous diverse intestinal immunological functions is achieved through the immunological crosstalk among immunocompetent cells via endogenous molecules (e.g., cytokines and chemokines). In addition to these endogenous factors, components of the gut environment, such as commensal bacteria and dietary materials, influence intestinal immunological functions. Recent advances in genetic identification have revealed that commensal bacteria play an important role in the development and maintenance of not only intestinal or mucosal immunity but also the host immune system [reviewed in Ref. (6)]. Although the underlying molecular and cellular mechanisms are not fully understood, nutritional components derived from the diet, either directly absorbed or metabolized or synthesized de novo by commensal bacteria, clearly are essential and influential exogenous factors for the development, maintenance, and regulation of the intestinal immune system $(7,8)$. This idea is underscored by the fact that nutrient deficiencies often are associated with impaired intestinal immunity (9). For instance, a recent study shows that angiotensin I converting enzyme 2 regulates intestinal amino acid metabolism and consequently affects the ecology of commensal bacteria, which leads to the transmittable colitis (10). Another recent study has demonstrated that commensal bacteria from kwashiorkor, a form of acute malnutrition that occurs by inadequate intake of dietary protein, perturb the metabolism of amino acids and carbohydrates (11).

Vitamins are organic compounds that the host organism cannot synthesize in sufficient quantities and that therefore need to 
be supplied exogenously by the diet or commensal bacteria. Some vitamins (e.g., vitamin B family and vitamin C) are water-soluble, whereas others (e.g., vitamins A, D, E, and K) are hydrophobic. Both hydrophilic and hydrophobic vitamins and their metabolites have diverse functions in many biologic events, including immunologic regulation. Indeed, vitamin deficiency results in high susceptibility to infection and immune diseases (12). Previously vitamins were thought to regulate the immune system in an indiscriminant manner, but accumulating evidence has revealed specific functions of individual vitamins and their metabolites in immune responses.

In this review, we discuss recent progress regarding our understanding of the immunologic functions of particular vitamins and their contributions toward maintaining the immunologic balance between physiologic and pathologic conditions of the intestine.

\section{VITAMIN A REGULATES CELL TRAFFICKING AND DIFFERENTIATION IN THE INTESTINE}

Vitamin A, especially its metabolite retinoic acid (RA), has emerged as a critical mediator of mucosal immune responses [reviewed in Ref. (13)]. Vitamin A is a fat-soluble essential micronutrient obtained from diets as all-trans-retinol, retinyl esters, or $\beta$-carotene and is metabolized into retinol in tissues (14). Retinol then is converted mainly to the all-trans isoform of RA through oxidation by alcohol dehydrogenases $(\mathrm{ADH})$ and retinaldehyde dehydrogenases (RALDH) (Figure 1).

The importance of vitamin $\mathrm{A}$ in the regulation of intestinal immunity has long been indicated. Indeed, vitamin A deficiency leads to increased susceptibility to various pathogens and

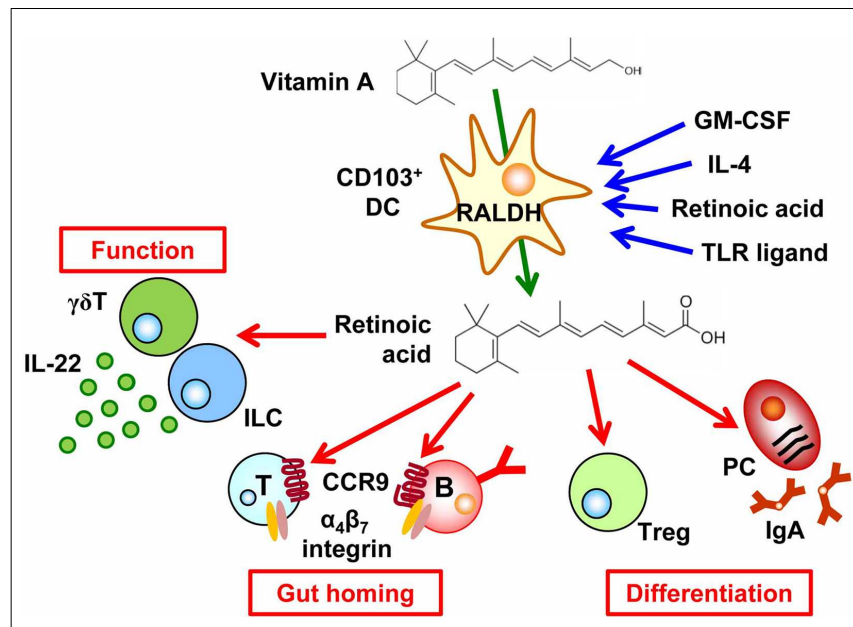

FIGURE 1 | Regulation of cell trafficking, differentiation, and function by the vitamin A metabolite retinoic acid. $C D 103^{+}$dendritic cells (DCs) express retinaldehyde dehydrogenases (RALDH) by GM-CSF, IL-4, TLR ligand, and retinoic acid (RA), which enable them to convert vitamin $A$ into RA. RA then induces CCR9 and $\alpha 4 \beta 7$ integrin in T and B cells, causing them to migrate into the intestine. In addition, retinoic acid affects cell differentiation, such as the preferential differentiation of $\mathrm{T}$ cells into regulatory $T\left(T_{\text {reg }}\right)$ cells and $B$ cells into IgA-producing plasma cells (PCs). RA also enhances IL-22 production from $\gamma \delta T$ cells and innate lymphoid cells. vitamin A supplementation reduces the morbidity and mortality due to infectious diseases (e.g., diarrheal infections and measles) (15). During the past few years, our molecular and cellular understanding of the roles of vitamin $\mathrm{A}$ in the regulation of intestinal immunity has increased greatly. A key discovery was that RA regulates cell trafficking by inducing the expression of the gut-homing molecules $\alpha 4 \beta 7$ integrin and chemokine receptor CCR9 on lymphocytes and thus determining the gut tropism of these cells $(16,17)$. Epithelial cells and DCs, especially CD $103^{+}$DCs, in the intestine uniquely express RALDH and thus are capable of synthesizing RA; therefore the lymphocytes activated by intestinal DCs and epithelial cells express $\alpha 4 \beta 7$ integrin and CCR9, which allow them to return to the intestinal compartment (Figure 1). In agreement with this understanding, vitamin-A-deficient mice lack $\mathrm{T}$ cells and IgA-PCs in the intestine $(16,17)$. Several lines of evidence have demonstrated that GM-CSF induces the RALDH expression in DCs and RA itself, IL-4, and MyD88-mediated toll-like receptor pathway enhance the induction of RALDH expression (Figure 1) $(18,19)$.

Retinoic acid plays an important role in determining not only the gut tropism of lymphocytes activated in the intestine but also cell differentiation. For example, through the cooperative effects of TGF- $\beta$, RA promotes class switching of $\operatorname{IgM}^{+}$B cells to those expressing IgA (Figure 1). Therefore, antagonism of RA results in reduced IgA production $(17,20)$. Another study demonstrated that Runx proteins mediate effects downstream of RA and TGF- $\beta 1$ signaling in IgA class switching (21).

In addition to the effects of RA on DCs and B cells, RA affects $\mathrm{T}$ cell differentiation. Indeed, preferential differentiation of $\mathrm{T}$ cells into $\mathrm{T}_{\text {reg }}$ cells is mediated by $\mathrm{CD}_{103}{ }^{+}$DCs that are capable of producing RA and activating latent TGF- $\beta$ (22-24). Reciprocally, RA failed to enhance differentiation of naïve $\mathrm{T}$ cells into Th17 cells in the absence of DCs (25). In this regard, DCs in the intestinal lamina propria of vitamin-A-deficient mice reportedly show impaired production of IL-6, a cytokine that is essential in the differentiation of Th17 cells (26) although there are controversial reports on the production of IL- 6 by MLN-DCs from vitamin-Adeficient mice (27). On the other hand, RA-RA receptor $\alpha$ signal in $\mathrm{T}$ cells requires $\mathrm{T}$ cell effector responses regardless $\mathrm{T}$ cell subsets (26), which is in line with a previous report that Th17 cells require a low concentration of RA (20). In agreement with these functions of RA, vitamin-A-deficient mice have decreased numbers of both $\mathrm{T}_{\text {reg }}$ and Th17 cells in the intestine mainly due to the defect of $\mathrm{T}$ cell trafficking into the small intestine $(25,26$, 28). In addition, segmented filamentous bacteria, Th17-inducing commensal bacteria, is decreased in vitamin A-deficient condition by high levels of mucin by goblet cells, which also leads to the impaired Th17 cell differentiation (29). Taken together, intrinsic and extrinsic factors for $\mathrm{T}$ cell differentiation are affected by the RA.

In addition to conventional $\alpha \beta \mathrm{T}$ cells, a recent study has demonstrated that RA enhanced IL-22 production by $\gamma \delta \mathrm{T}$ cells and innate lymphoid cells, which are involved in the attenuation of intestinal inflammation (30). RA also affects non-lymphoid cells in the lymph node initiation. Indeed, RA produced by neurons 
adjacent to the lymph node anlagen induced CXC13 expression in stromal organizer cells and consequently led to the initial clustering of lymphoid tissue inducer cells (31). Therefore, RA has diverse functions in the regulation of versatile immunological events including cell trafficking, differentiation, cytokine production, and lymphoid organogenesis.

The various roles of RA in the mucosal immune system, especially regulating cell trafficking into the intestine, enable us to consider clinical applications of this metabolite. In general, parenteral immunization fails to achieve efficient antigen-specific immune responses in the intestine because it does not induce the necessary gut-homing molecules for the migration of antigen-sensitized immune cells into the intestine. A recent study demonstrated that the addition of RA at the time of subcutaneous vaccination increased the accumulation of antigen-specific $\mathrm{T}$ cells and IgA-producing PCs in the intestine and concurrently induced protective immunity against intestinal pathogens (e.g., Salmonella) (32). These findings suggest that exogenous RA treatment might be used to stimulate the production of gut-migrating $\mathrm{T}_{\text {reg }}$ cells for the control of intestinal inflammation and allergy. Additional investigation into the immune functions of RA is warranted to advance potential clinical applications of this vitamin A metabolite.

\section{MEMBERS OF THE VITAMIN B FAMILY CONTROL CELL METABOLISM AND ACTS AS LIGANDS IN THE REGULATION OF INTESTINAL IMMUNITY}

Initially thought to be a single vitamin, vitamin B currently is recognized as a family comprising eight different members. All $B$ vitamins are water-soluble, and they are involved in various pathways of cell metabolism. Among the B vitamins, vitamin B6 is essential for metabolism of nucleic acids, amino acids, and lipids and thus influences cell growth. Consequently, vitamin B6 deficiency leads to various impairments of immunity, such as lymphoid atrophy and reduced numbers of lymphocytes (33); conversely, vitamin B6 supplementation bolsters these weakened immune responses (34). A previous study suggested the involvement of the lipid mediator sphingosine 1-phosphate (S1P) in vitamin-B6-mediated immune regulation. S1P has been shown to regulate cell trafficking, especially cell egress from organized lymphoid tissues in both systemic (e.g., thymus, bone marrow, and lymph nodes) and mucosal (e.g., intestine) compartments [reviewed in Refs. $(35,36)]$. The cell trafficking is determined by the S1P gradient that is achieved through the coordinated production of S1P and its degradation, which is mediated by S1P lyase and S1P phosphohydrolase (35). S1P lyase requires vitamin B6 as a co-factor for the degradation of S1P (37), and the administration of a vitamin B6 antagonist impair S1P lyase activity and thus create an inappropriate S1P gradient. These defects lead to impaired trafficking of lymphocytes from lymphoid tissues and consequently reduced numbers of lymphocytes in the periphery $(38,39)$.

Like vitamin B6, vitamin B9 (that is, folate or folic acid) is essential for nucleic acid and protein synthesis (40), and inadequate levels of vitamin B9 dramatically alter the immune response. Previous studies suggested that vitamin B9 deficiency inhibits the

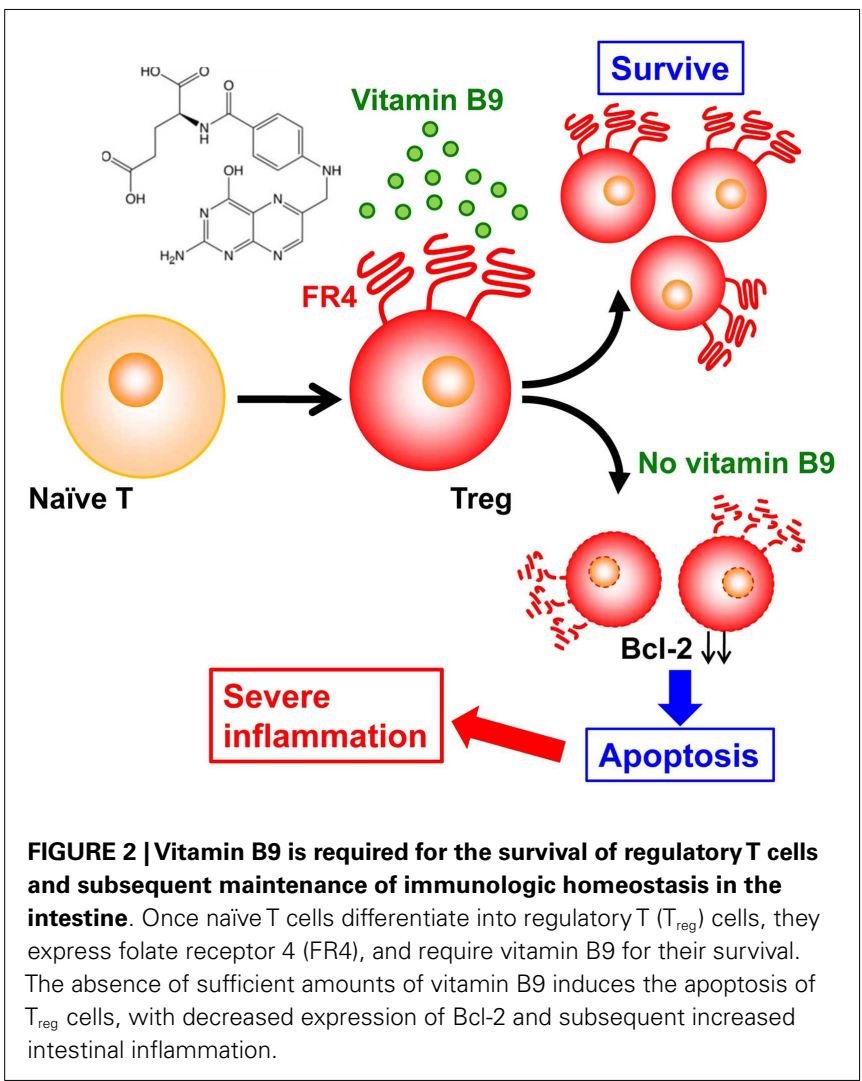

activity of $\mathrm{CD}^{+} \mathrm{T}$ cells and NK cells; in turn, this inhibition is associated with decreased resistance to infections (41).

Folate receptor 4, a vitamin B9 receptor, is highly expressed on the surfaces of $\mathrm{T}_{\text {reg }}$ cells (42), implying a specific function of this vitamin in these cells. In particular, our recent study revealed that vitamin $\mathrm{B} 9$ is crucial in the maintenance of $\mathrm{T}_{\text {reg }}$ cells (43). In the absence of vitamin B9, naïve $\mathrm{T}$ cells can differentiate into $\mathrm{T}_{\text {reg }}$ cells, but differentiated $\mathrm{T}_{\text {reg }}$ cells fail to survive owing to the decreased expression of anti-apoptotic molecules (e.g., Bcl-2) (Figure 2). As a result, mice maintained on a vitaminB9-deficient diet have decreased numbers of intestinal $\mathrm{T}_{\text {reg }}$ cells (43). As a result, the impaired survival of $\mathrm{T}_{\text {reg }}$ cells in these mice leads to their increased susceptibility to intestinal inflammation (Figure 2) (44).

A recent study demonstrated an additional function of the vitamin B family in the control of immune responses via mucosaassociated invariant T (MAIT) cells. MAIT cells are unconventional $\mathrm{T}$ cells that express a semi-invariant $\alpha \beta$ T cell receptor that is restricted by the MHC class I-related molecule MR1; these cells are mostly found in the intestine, liver, and lung (45). Because MAIT cells can react rapidly to bacterial infections (e.g., Escherichia coli, Klebsiella pneumoniae, and Mycoplasma tuberculosis), it was supposed that the antigen presented to MR1 was bacteria-derived molecules. However, a recent study clarified that, in fact, bacterially produced metabolites of vitamin B9 and vitamin B2 bound to MR1 are presented as antigen to MAIT cells (46). Furthermore, like vitamin B2 derivatives, the vitamin B9 metabolite 6-formyl 


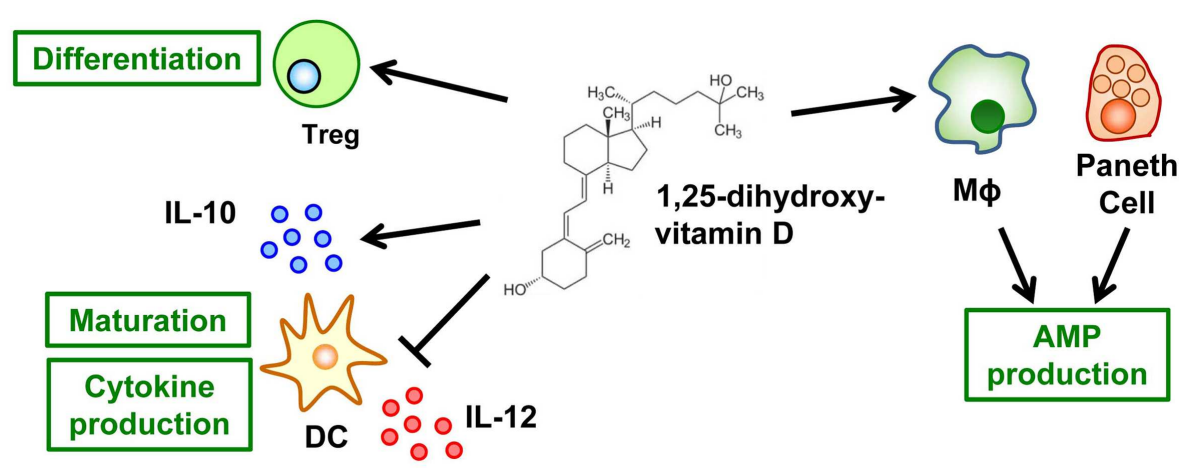

FIGURE 3 | Vitamin D mediates innate and acquired immunity. The active form of vitamin D, it metabolite 1,25-dihydroxyvitamin D, inhibits the maturation of dendritic cells (DCs) and their production of IL-12 but simultaneously promotes their production of IL-10. In addition, T cells respond directly to 1,25-dihydroxyvitamin $\mathrm{D}$ for their preferential differentiation into $\mathrm{T}_{\text {reg }}$ cells. As a component of innate immunity, 1,25-dihydroxyvitamin D promotes the production of anti-microbial peptides (AMP) by macrophages and Paneth cells. pterin binds to MR1 but, unlike vitamin B2 derivatives, fails to activate MAIT cells (46). These findings suggest that, depending on their metabolism by commensal bacteria and presentation by MR1, members of the vitamin B family can act either as positive or negative regulatory ligands for MAIT cells.

\section{VITAMIN D IS AN INHIBITOR OF IMMUNE RESPONSES}

In its typical role of maintaining optimal concentrations of serum calcium, vitamin D is essential to a healthy mineralized skeleton (47). In addition to its effects on calcium and bone metabolism, vitamin $\mathrm{D}$ - especially its metabolite 1,25-dihydroxyvitamin $\mathrm{D}$ $\left[1,25(\mathrm{OH})_{2} \mathrm{D}\right]-$ is an important regulator of the immune system, and its deficiency is linked to aberrant immune responses, including intestinal inflammation (48). Regarding a possible mechanism linking vitamin $\mathrm{D}$ and intestinal inflammation, $1,25(\mathrm{OH})_{2} \mathrm{D}$ may be important in the creation of an immunologic regulatory or suppressor environment. For example, $1,25(\mathrm{OH})_{2} \mathrm{D}$ inhibits the maturation of DCs and the production of their effector cytokine, IL-12, and simultaneously promotes the production of their inhibitory cytokine, IL-10, thus regulating T cell function and development (Figure 3) (49). In addition, T cells directly respond to $1,25(\mathrm{OH})_{2} \mathrm{D}$, with preferential differentiation into $\mathrm{T}_{\text {reg }}$ cells (Figure 3) (50).

Furthermore, vitamin D enhances innate immunity (Figure 3). More than 25 years have passed since the anti-microbial function of $1,25(\mathrm{OH})_{2} \mathrm{D}$ against Mycobacterium tuberculosis in human monocytes was reported (51). Subsequent studies have revealed the molecular and cellular mechanisms underlying this antimicrobial activity. Once they are activated through Toll-like receptors, macrophages-monocytes express CYP27B1, a key enzyme in the synthesis of $1,25(\mathrm{OH})_{2} \mathrm{D}(52)$, and the vitamin $\mathrm{D}$ receptor (VDR) (53). These changes lead to intracrine synthesis of $1,25(\mathrm{OH})_{2} \mathrm{D}$, which enhances the gene expression mediated by vitamin D and the VDR axis. VDR-mediated genes include the antimicrobial molecules cathelicidin (LL-37) and $\beta$-defensin 2 (54). Similar $1,25(\mathrm{OH})_{2} \mathrm{D}$-induced production of these anti-microbial molecules occurs in epithelial cells (55) and Paneth cells (56). In addition, 1,25( $\mathrm{OH})_{2} \mathrm{D}$ stabilizes tight-junction structures between epithelial cells in the intestinal tract (57). Together, these diverse functions of vitamin D contribute to the creation of the first line of defense against pathogens without the induction of aberrant inflammatory responses.

\section{CONCLUSION}

Clinical evidence has long indicated that inadequate vitamin intake disrupts host immunity, thus predisposing humans to infectious and inflammatory diseases. Accumulating evidence has revealed the molecular and cellular mechanisms underlying myriad functions of vitamins in innate and acquired immune responses. These findings clarify the beneficial roles of vitamins in the maintenance of immunologic homeostasis and inform the design of vitamin analogs as pharmacologic agents for the generation and maintenance of a healthy immune condition. The complex functions of vitamins in the regulation of the immune system merit continued investigation, and these research efforts likely will enable scientists to refine our understanding of the mechanisms underlying the immunologic roles of various vitamins and to advance the development of vitamin-dependent therapeutic agents for the control of infectious and immune diseases.

\section{ACKNOWLEDGMENTS}

Work featured in this review article was supported by grants from the Program for Promotion of Basic and Applied Research for Innovations in Bio-oriented Industry (to Jun Kunisawa); the Ministry of Education, Culture, Sports, Science, and Technology of Japan [Grants-in-Aid for Scientific Research on Innovative Areas (25116706 to Jun Kunisawa), for Challenging Exploratory Research (24659217 to Jun Kunisawa), for Scientific Research S (23229004 to Hiroshi Kiyono), and for the Leading-edge Research Infrastructure Program (to Jun Kunisawa and Hiroshi Kiyono)]; the Ministry of Health and Welfare of Japan (to Jun Kunisawa and Hiroshi Kiyono); and the Yakult Bio-Science Foundation (to Jun Kunisawa). 


\section{REFERENCES}

1. Kiyono H, Kunisawa J, McGhee JR, Mestecky J. The mucosal immune system. In: Paul WE editor. Fundamental Immunology. Vol 6, Philadelphia: Lippincott-Raven (2008). p. 983-1030.

2. Pabst O, Mowat AM. Oral tolerance to food protein. Mucosal Immunol (2012) 53:232-9. doi:10.1038/mi.2012.4

3. Spits $H$, Artis D, Colonna $M$, Diefenbach A, Di Santo JP, Eberl $\mathrm{G}$, et al. Innate lymphoid cells a proposal for uniform nomenclature. Nat Rev Immunol (2013) 132:145-9. doi:10.1038/nri3365

4. Scott CL, Aumeunier AM, Mowat AM. Intestinal $\mathrm{CD}_{103}{ }^{+}$ dendritic cells: master regulators of tolerance? Trends Immunol (2011) 329:412-9. doi:10.1016/j.it.2011.06.003

5. Kim JS, Sampson HA. Food allergy: a glimpse into the inner workings of gut immunology. Curr Opin Gastroenterol (2012) 282:99-103. doi:10.1097/ MOG.0b013e32834e7b60

6. Ivanov II, Honda K. Intestinal commensal microbes as immune modulators. Cell Host Microbe (2012) 124:496-508. doi:10.1016/j.chom.2012.09.009

7. Veldhoen M, BrucklacherWaldert V. Dietary influences on intestinal immunity. Nat Rev Immunol (2012) 1210:696-708. doi:10.1038/nri3299

8. Spencer SP, Belkaid Y. Dietary and commensal derived nutrients: shaping mucosal and systemic immunity. Curr Opin Immunol (2012) 244:379-84. doi:10.1016/j.coi.2012.07.006

9. Hanson LA, Robertson A-K and Bjersing J. Undernutrition, immunodeficiency, and mucosal infections. In: Mestecky J, Lamm ME, Strober W, Bienenstock J, McGhee JR, Mayer L editors. Mucosal Immunology. 3rd ed. San Diego: Academic Press (2005). p. 1159-78.

10. Hashimoto T, Perlot T, Rehman A, Trichereau J, Ishiguro H, Paolino $\mathrm{M}$, et al. ACE2 links amino acid malnutrition to microbial ecology and intestinal inflammation. Nature (2012) 4877408:477-81. doi:10.1038/nature11228

11. Smith MI, Yatsunenko T, Manary MJ, Trehan I, Mkakosya R, Cheng J, et al. Gut microbiomes of Malawian twin pairs discordant for kwashiorkor. Science (2013) 3396119:548-54. doi:10.1126/science. 1229000
12. Bhaskaram P. Micronutrient malnutrition, infection, and immunity: an overview. Nutr Rev (2002) 605(Pt 2):S40-5. doi:10.1301/00296640260130722

13. Iwata M. Retinoic acid production by intestinal dendritic cells and its role in T-cell trafficking. Semin Immunol (2009) 211:8-13. doi:10.1016/j.smim.2008.09.002

14. Theodosiou M, Laudet V, Schubert M. From carrot to clinic: an overview of the retinoic acid signaling pathway. Cell $\mathrm{Mol}$ Life Sci (2010) 679:1423-45. doi:10.1007/s00018-010-0268-z

15. Villamor E, Fawzi WW. Effects of vitamin a supplementation on immune responses and correlation with clinical outcomes. Clin Microbiol Rev (2005) 183:446-64. doi:10.1128/CMR.18.3.446464.2005

16. Iwata $M$, Hirakiyama A, Eshima Y, Kagechika H, Kato C, Song SY. Retinoic acid imprints guthoming specificity on $\mathrm{T}$ cells. Immunity (2004) 214:527-38. doi:10.1016/j.immuni.2004.08.011

17. Mora JR, Iwata M, Eksteen B, Song SY, Junt T, Senman B, et al. Generation of gut-homing IgA-secreting $B$ cells by intestinal dendritic cells. Science (2006) 3145802:1157-60. doi:10.1126/science.1132742

18. Yokota A, Takeuchi H, Maeda N, Ohoka Y, Kato C, Song SY, et al. GM-CSF and IL-4 synergistically trigger dendritic cells to acquire retinoic acid-producing capacity. Int Immunol (2009) 214:361-77. doi:10.1093/intimm/dxp003

19. Villablanca EJ, Wang S, de Calisto J, Gomes DC, Kane MA, Napoli $\mathrm{JL}$, et al. MyD88 and retinoic acid signaling pathways interact to modulate gastrointestinal activities of dendritic cells. Gastroenterology (2011) 1411:176-85. doi:10.1053/j.gastro.2011.04.010

20. Uematsu S, Fujimoto K, Jang MH, Yang BG, Jung YJ, Nishiyama $\mathrm{M}$, et al. Regulation of humoral and cellular gut immunity by lamina propria dendritic cells expressing Toll-like receptor 5 . Nat Immunol (2008) 97:769-76. doi:10.1038/ni.1622

21. Watanabe K, Sugai M, Nambu Y, Osato M, Hayashi T, Kawaguchi $\mathrm{M}$, et al. Requirement for Runx proteins in IgA class switching acting downstream of TGF$\beta 1$ and retinoic acid signaling. J Immunol (2010) 1846:2785-92. doi:10.4049/jimmunol.0901823

22. Coombes JL, Siddiqui KR, Arancibia-Cárcamo CV, Hall
J, Sun CM, Belkaid Y, et al. A functionally specialized population of mucosal $\mathrm{CD}_{103^{+}} \mathrm{DCs}$ induces $\mathrm{Foxp}^{+}$regulatory $\mathrm{T}$ cells via a TGF- $\beta$ and retinoic acid-dependent mechanism. J Exp Med (2007) 2048:1757-64. doi:10.1084/jem.20070590

23. Mucida D, Park Y, Kim G, Turovskaya O, Scott I, Kronenberg $\mathrm{M}$, et al. Reciprocal Th17 and regulatory $\mathrm{T}$ cell differentiation mediated by retinoic acid. Science (2007) 3175835:256-60. doi:10.1126/science.1145697

24. Sun CM, Hall JA, Blank RB, Bouladoux N, Oukka M, Mora JR, et al. Small intestine lamina propria dendritic cells promote de novo generation of Foxp3 Treg cells via retinoic acid. J Exp Med (2007) 2048:1775-85. doi:10.1084/jem.20070602

25. Wang C, Kang SG, HogenEsch $\mathrm{H}$, Love PE, Kim CH. Retinoic acid determines the precise tissue tropism of inflammatory Th17 cells in the intestine. $J$ Immunol (2010) 18410:5519-26. doi:10.4049/jimmunol.0903942

26. Hall JA, Cannons JL, Grainger JR, Dos Santos LM, Hand TW, Naik S, et al. Essential role for retinoic acid in the promotion of $\mathrm{CD}^{+} \mathrm{T}$ cell effector responses via retinoic acid receptor $\alpha$. Immunity (2011) 343:435-47. doi:10.1016/j.immuni.2011.03.003

27. Chang JH, Cha HR, Chang SY, Ko HJ, Seo SU, Kweon MN. IFN- $\gamma$ secreted by $\mathrm{CD} 03^{+}$dendritic cells leads to IgG generation in the mesenteric lymph node in the absence of vitamin A. J Immunol (2011) 18612:6999-7005. doi:10.4049/jimmunol.1003484

28. Takahashi H, Kanno T, Nakayamada S, Hirahara K, Sciumè G, Muljo SA, et al. TGF- $\beta$ and retinoic acid induce the microRNA miR10a, which targets Bcl-6 and constrains the plasticity of helper $\mathrm{T}$ cells. Nat Immunol (2012) 136:587-95. doi:10.1038/ni.2286

29. Cha HR, Chang SY, Chang JH, Kim JO, Yang JY, Kim $\mathrm{CH}$, et al. Downregulation of Th17 cells in the small intestine by disruption of gut flora in the absence of retinoic acid. $J$ Immunol (2010) 18412:6799-806. doi:10.4049/jimmunol.0902944

30. Mielke LA, Jones SA, Raverdeau M, Higgs R, Stefanska A, Groom $J R$, et al. Retinoic acid expression associates with enhanced IL-22 production by $\gamma \delta \mathrm{T}$ cells and innate lymphoid cells and attenuation of intestinal inflammation. $J \quad \operatorname{Exp}$ Med (2013) 2106:1117-24. doi:10.1084/jem.20121588

31. van de Pavert SA, Olivier BJ, Goverse G, Vondenhoff MF, Greuter $\mathrm{M}$, Beke $\mathrm{P}$, et al. Chemokine CXCL13 is essential for lymph node initiation and is induced by retinoic acid and neuronal stimulation. Nat Immunol (2009) 1011:1193-9. doi:10.1038/ni.1789

32. Hammerschmidt SI, Friedrichsen M, Boelter J, Lyszkiewicz M, Kremmer E, Pabst O, et al. Retinoic acid induces homing of protective $\mathrm{T}$ and $\mathrm{B}$ cells to the gut after subcutaneous immunization in mice. JClin Invest (2011) 1218:3051-61. doi:10.1172/JCI44262

33. Rall LC, Meydani SN. Vitamin B6 and immune competence. Nutr Rev (1993) 518:217-25.

34. Talbott MC, Miller LT, Kerkvliet NI. Pyridoxine supplementation: effect on lymphocyte responses in elderly persons. Am J Clin Nutr (1987) 464:659-64.

35. Cyster JG, Schwab SR. Sphingosine-1-phosphate and lymphocyte egress from lymphoid organs. Annu Rev Immunol (2012) 30:69-94. doi:10.1146/annurevimmunol-020711-075011

36. Kunisawa J, Kiyono H. Immunological function of sphingosine 1-phosphate in the intestine. Nutrients (2012) 43:154-66. doi:10.3390/nu4030154

37. Ikeda M, Kihara A, Igarashi Y. Sphingosine-1-phosphate lyase SPL is an endoplasmic reticulum-resident, integral membrane protein with the pyridoxal 5'phosphate binding domain exposed to the cytosol. Biochem Biophys Res Commun (2004) 3251:338-43. doi:10.1016/ j.bbrc.2004.10.036

38. Schwab SR, Pereira JP, Matloubian M, Xu Y, Huang Y, Cyster JG. Lymphocyte sequestration through S1P lyase inhibition and disruption of S1P gradients. Science (2005) 3095741:1735-9. doi:10.1126/ science. 1113640

39. Kunisawa J, Kurashima Y, Higuchi M, Gohda M, Ishikawa I, Ogahara I, et al. Sphingosine 1phosphate dependence in the regulation of lymphocyte trafficking to the gut epithelium. $J$ Exp Med (2007) 20410:233548. doi:10.1084/jem.20062446

40. Stover PJ. Physiology of folate and vitamin B12 in health and disease. Nutr Rev (2004) 626(Pt 2):S3-12. 
doi:10.1111/j.1753-4887.2004. tb00070.x discussion S13,

41. Troen AM, Mitchell B, Sorensen $\mathrm{B}$, Wener MH, Johnston A, Wood B, et al. Unmetabolized folic acid in plasma is associated with reduced natural killer cell cytotoxicity among postmenopausal women. J Nutr (2006) 1361:18994.

42. Yamaguchi $T$, Hirota $K$, Nagahama $\mathrm{K}$, Ohkawa $\mathrm{K}$, Takahashi $\mathrm{T}$, Nomura $\mathrm{T}$, et al. Control of immune responses by antigenspecific regulatory $\mathrm{T}$ cells expressing the folate receptor. Immunity (2007) 271:145-59. doi:10.1016/j.immuni.2007.04.017

43. Kunisawa J, Hashimoto E, Ishikawa I, Kiyono H. A pivotal role of vitamin B9 in the maintenance of regulatory $\mathrm{T}$ cells in vitro and in vivo. PLoS ONE (2012) 72:e32094. doi:10.1371/journal.pone.0032094

44. Kinoshita M, Kayama H, Kusu T, Yamaguchi T, Kunisawa J, Kiyono $\mathrm{H}$, et al. Dietary folic acid promotes survival of $\mathrm{Foxp}^{+}$regulatory $\mathrm{T}$ cells in the colon. $J$ Immunol (2012) 1896:2869-78. doi:10.4049/jimmunol.1200420

45. Le Bourhis L, Guerri L, Dusseaux M, Martin E, Soudais C, Lantz O. Mucosal-associated invariant $\mathrm{T}$ cells: unconventional development and function. Trends Immunol (2011) 325:212-8. doi:10.1016/j.it.2011. 02.005

46. Kjer-Nielsen L, Patel O, Corbett AJ, Le Nours J, Meehan B, Liu L, et al. MR1 presents microbial vitamin B metabolites to MAIT cells. Nature (2012) 4917426:717-23. doi:10.1038/nature11605

47. Holick MF. Vitamin D and bone health. J Nutr (1996) 126(Suppl 4):1159S-64.

48. Iijima $\mathrm{H}$, Shinzaki S, Takehara $\mathrm{T}$. The importance of vitamins $D$ and $\mathrm{K}$ for the bone health and immune function in inflammatory bowel disease. Curr Opin Clin Nutr Metab Care (2012) 156:635-40. doi:10.1097/MCO.0b013e328357 f623

49. Penna G, Adorini L. $1 \alpha, 25-$ dihydroxyvitamin D3 inhibits differentiation, maturation, activation, and survival of dendritic cells leading to impaired alloreactive $\mathrm{T}$ cell activation. J Immunol (2000) 1645:2405-11.

50. Gorman S, Kuritzky LA, Judge MA, Dixon KM, McGlade JP, Mason RS, et al. Topically applied 1,25-dihydroxyvitamin D3 enhances the suppressive activity of $\mathrm{CD} 4{ }^{+} \mathrm{CD} 25^{+}$cells in the draining lymph nodes. $J$ Immunol (2007) 1799:6273-83.

51. Rook GA, Steele J, Fraher L, Barker S, Karmali R, O’Riordan
J, et al. Vitamin D3, $\gamma$ interferon, and control of proliferation of Mycobacterium tuberculosis by human monocytes. Immunology (1986) 571:159-63.

52. Schuster I. Cytochromes P450 are essential players in the vitamin D signaling system. Biochim Biophys Acta (2011) 18141:18699. doi:10.1016/j.bbapap.2010. 06.022

53. Liu PT, Stenger S, Li H, Wenzel L, Tan BH, Krutzik SR, et al. Toll-like receptor triggering of a vitamin D-mediated human antimicrobial response. Science (2006) 3115768:1770-3. doi:10.1126 science. 1123933

54. Wang TT, Nestel FP, Bourdeau V, Nagai Y, Wang Q, Liao $\mathrm{J}$, et al. Cutting edge: 1,25dihydroxyvitamin D3 is a direct inducer of antimicrobial peptide gene expression. JImmunol (2004) 1735:2909-12.

55. Yim S, Dhawan P, Ragunath C, Christakos S, Diamond G. Induction of cathelicidin in normal and $\mathrm{CF}$ bronchial epithelial cells by 1,25dihydroxyvitamin D3. JCyst Fibros (2007) 66:403-10. doi:10.1016/ j.jcf.2007.03.003

56. Gombart AF. The vitamin Dantimicrobial peptide pathway and its role in protection against infection. Future
Microbiol (2009) 49:1151-65. doi:10.2217/fmb.09.87

57. Fujita $H$, Sugimoto $K$, Inatomi $S$, Maeda T, Osanai M, Uchiyama $\mathrm{Y}$, et al. Tight junction proteins claudin-2 and -12 are critical for vitamin D-dependent $\mathrm{Ca}^{2+}$ absorption between enterocytes. Mol Biol Cell (2008) 195:1912-21. doi:10.1091/mbc.E07-09-0973

Conflict of Interest Statement: The research was conducted in the absence of any commercial or financial relationships that could be construed as a potential conflict of interest.

Received: 22 April 2013; paper pending published: 02 June 2013; accepted: 26 June 2013; published online: 11 July 2013. Citation: Kunisawa $J$ and Kiyono $H$ (2013) Vitamin-mediated regulation of intestinal immunity. Front. Immunol. 4:189. doi: 10.3389/fimmu.2013.00189

This article was submitted to Frontiers in Mucosal Immunity, a specialty of Frontiers in Immunology.

Copyright $\odot 2013$ Kunisawa and Kiyono. This is an open-access article distributed under the terms of the Creative Commons Attribution License, which permits use, distribution and reproduction in other forums, provided the original authors and source are credited and subject to any copyright notices concerning any third-party graphics etc. 